\title{
Knowledge and Use of Contraceptives among Tertiary Education Students in South Africa
}

\author{
M. Makhaza1 \\ K.D. $\lg \mathrm{e}^{2}$ \\ 1,2Department of Sociology, University of Zululand, P/bag X1001, KwaDlangezwa, 3886, South Africa \\ Mchotty17@webmail.co.za1; igedavies@gmail.com²
}

Doi:10.5901/mjss.2014.v5n10p500

\section{Abstract}

This study investigated the knowledge, use and problems encountered with contraceptives among students at the University of Zululand. The study purposed to determine students' levels of use and knowledge of contraceptives, to examine if the students' use of contraceptives is determined by their knowledge of contraceptives and also to proffer useful solutions towards the use of contraceptives. Adopting a survey strategy and a sample size of 80 students $(n=66)$, data was collected using a questionnaire. Data analysis was conducted using the Statistical Package for the Social Sciences (SPSS). Scales was constructed using Principal Components Analysis (PCA). Relationships between variables were discerned using bivariate correlations. The results of the study showed that students' knowledge and use of contraceptives were determined by their social and demographic characteristics. The results further showed that there is a significant relationship between students' knowledge use and experience of problems in the use of contraceptive. On the basis of the findings, it was recommended that proper orientation about the correct use of contraceptives should be provided to new students.

Keywords: Teenage pregnancy; Sexually transmitted diseases; HIVIAIDS;

\section{Introduction}

Unplanned pregnancy is a major medical, social, and public health problem. This often results in induced abortion, which occurs at a relatively high rate (Ahman and Shah, 2007). The appropriate use of contraceptive has the great potential of reducing abortion and preventing unintended pregnancies. In addition, contraceptives play a significant role in reducing the spread of sexually transmitted diseases (Gama, 2008). Given the high prevalence of sexually transmitted diseases and unplanned pregnancies in Sub Saharan Africa, the promotion of contraceptives use has gained urgent attention of policy makers and international bodies devoted to the promotion of health and wellness. As the focus of these campaigns is often on youths who are most sexually active, it becomes important to determine motivators and hindrances to the effective use of contraceptives among this segment of the population. The preponderance of the young population are either at higher levels of education or high school level as such the understanding of knowledge and use of contraceptive among students becomes imperative. South Africa has a huge teen pregnancy problem - one in three girls has had a baby by the age of 20 (Sowetan live, 2011). It is clear that young people are not using contraceptives like condoms, so they are also exposing themselves to serious illnesses like Aids and STI.

\section{Consequences of Sexually Risky Behaviors among Youths}

Knowledge and use of contraceptives play a vital role in preventing various consequences that of failure to use contraceptives. When young people move out of their parents' homes direct parental control ceases and identification with the peer group increases. Parental advises are quickly forgotten and peer pressure takes over. In such conditions sexual intercourse is practiced with resultant pregnancy. Sexual education and talk about sex is one of the topics that are not usually discussed by members of a family (Gama, 2008). Teenagers who experience physiological and other challenges often find it very complicated to discuss these experiences with their parents and their siblings. Parents are not open to talk about sex with their children and children may find it difficult to talk about sex with their parents because parents often construe sex talk as an indication that the children are ready for sex. In need of information therefore, teenagers often seek information from friends. Consequently, wrong information is passed around. Other sources of information to teenagers include books, magazines articles, and videos. However, the information obtained from these 
sources may not all be correct. This increases the chances of teenagers experimenting with sex and they may end up pregnant or getting sexually transmitted disease including HIV and AIDS. The peer group also acts as another primary source of information about sex. This information may be incorrect in some instances. Studies showed that peer pressure is often the direct cause of an unplanned pregnancy (Corblin, 2006:352).

Much research has been done about the influence of the mass media on the peers (Barry, 1993:45). Today teenager have better opportunities to view sexual activity on cell phones, magazines, television and the internet more than ever before. Such information is accessible out of the context of the prescribed sexual norms of that society. This kind of information influences the teenager to internalize antisocial sexual behaviour or to experiment with illegal sexual activity, with resultant pregnancy. Together with peer pressure, the mass media has a powerful triggering effect on the teenage to indulge in illicit sex. The media also has an influence on attitudes of young people.

Alcohol and drug abuse also play a significant role in risky sexual behaviour including unwanted pregnancy and unprotected sexual intercourse. Alcohol and drug abuse behaviour increase the risk for unwanted pregnancy and for contacting sexually transmitted diseases. The more young people drink and use drugs the less they use condoms or contraceptive methods. According to Chimere-Dan (1996:4-9), males are nearly twice as likely to mix alcohol or drugs but young women face greater threats. Not only do young women risk unplanned pregnancy, they are more likely to be the victim of alcohol or drug related sexual assault or an incurable STI. Chimere-Dan (1996:4-9) reported that 40\% of high school boys stated that it is acceptable to force sex if a girl is drunk. For adolescents therefore, there is a strong association of drug and alcohol use and different sex partners. The only way to avoid unplanned pregnancy and STI's is not to have sex or by using the most effective birth control e.g. condoms and thus protect against HIV. Gama (2008) showed that female students who are sexually active were more likely not to use contraceptives, which puts them at a high risk of unplanned pregnancy. Some are influenced by their partners regarding birth control or they forget to use contraceptives altogether.

University students engage in sexual intercourse, generally with multiple partners. Students are thus faced with the problem of unplanned pregnancies, which is increasing at a very high rate. Past studies found that the young adults (1519 years of age) are most affected by unplanned pregnancies. In addition, there is a racial dimension as studies showed that Black Africans accounted for a higher per cent of unmarried females experiencing unplanned pregnancy than other racial groups (Gama, 2008). The decline in the numbers of people using contraceptives therefore indicates that there is lot that needs to be done in educating and equipping people about the usefulness of contraceptives. Clinton (1990; 90 cited by Story (1999) found that $23 \%$ of the females indicated that pregnancy was caused by girls seeking to prove their fertility. This perception might lead females to engage in unprotected sexual intercourse without using any contraceptives so as to prove their fertility. The desire to prove fertility may have influenced some females' not to use contraceptives. Similarly, males want to prove their virility and often insist girls prove their 'love' or commitment to them.

\subsection{The consequences of unplanned pregnancy}

Little descriptive knowledge about the experience of unplanned pregnancy for university women exists. Most tertiary education and college students engage in sexual activity generally with different partners. Most of the sexually active students do not use any contraceptives. As a result, many college students experienced unplanned pregnancy. Studies showed that women experienced a significant number of long term effects related with the unplanned pregnancy. The most dominant of these effects are feelings of guilt and distress of being stigmatized for their experience. The guilt makes it challenging for them to interact with peers and family. The guilt, shame, fear, and sense of stigma reported are not just individual attributes but a reflection of wider social views about women's responsibility for sexuality and reproduction.

Furthermore, dropping out from school before completion often has a significant negative impact on the lives of the individuals. However, the costs go far beyond individual consequences. The dropping out of school has led to a serious economic and social repercussion for the larger society as well (McWhiter, 2004: 100). The individual who drops out of school before completing any course is at an economic disadvantage. Unemployment rates are very high among school drop-outs because those people they do not possess any skills. Thus they earn very low salaries compared to those who graduated. The economic consequence of the drop-out problem includes loss of earnings and taxes, loss of social security, and lack of qualified workers (McWhiter, 2004:101).

Leaving school before completing the program of study often has a negative impact on an individual's psychological well-being. The majority of students who drop-out later regret their decision to leave school; such dissatisfaction only intensifies the low self-esteem typical of potential dropouts. Dissatisfaction with self, with the environment, and with lack of job opportunity is also associated with lower occupational aspirations among young people (McWhiter, 2004: 102). School drop-outs are often unemployed or earn less money than their graduated people. Their 
children also experience negative consequence because they live in poor socioeconomic conditions. Proportionately few of these homes provide the study aids that children of graduates can expect to have. Parents who are not educated are less likely to provide schools-related activities for their children comparable to parents of higher socioeconomic status. In addition, parents who are drop-outs work such long hours that it is difficult for them to monitor their children's activities. Those parents who dropped out also have lower educational expectations for their own children. Young people who have babies at an early age are mostly dependent on their parents or government for support particularly child support grants. Some of those young mothers often come from the poor families. Young people who choose to keep their babies are more likely to suffer consequences in the form of health, poor housing, and poor nutrition and, unemployment and end to her schooling, have inadequate career training and suffer financial dependency (Robinson et al., 1993, cited by McWhither, 2004). Young mothers who are less or not educated do not develop the skills, resources and experience necessary to overcome poverty and the pervasive sense of powerlessness and vulnerability that usually accompanies it. Most young girls who carry their pregnancies to term decide to keep their babies. Those who grew up in poverty are given very little margin of error in negotiating the tasks of adolescence. Breaking this cycle and fostering young women's productive participation in society is critical to their adolescent parental role, their children, and society as a whole (McWhiter, 2004: 140). The educational challenges faced by adolescent parents are frequently carried over into the next generation. A disproportionate number of the children born to young mothers show more emotional and behavioural problems while growing up. In addition, these children have more erratic attendance records, lower grade point averages, lower scores on standardized achievement tests and lower college expectations (McWhiter, 2004). Teenagers who experience pregnancy are likely to experience poor health care, poor nutrition, prenatal, perinatal, and more postnatal problems than older mothers, and most of their babies die, likely because they seek prenatal care infrequently in their first trimester. Younger mothers stand high rates of giving birth to children with anaemia, toxaemia, STI's and uterine dysfunction and other complications of labour and delivery (Stevens-Simon \& White 1991). These problems are compounded for teenagers who live in poor socioeconomic conditions. Teenagers also have problems with premature delivery and are at greater risk of very long labour. Children of teenagers stand high chances of having serious health problems. For example, 15 year old mothers are more likely than older mothers to have low-birth weight babies and the baby is three times as likely to die in the first eight days of life. Low birth weight has been related to a number of developmental difficulties and learning disabilities (McWhiter, 2004: 141).

\subsubsection{Sex Education and Contraception}

Sources of information on contraceptives include parents or family members, school programs, doctors, clinics, friends, books and the internet. Women are less likely to experience an unplanned pregnancy if they received sex education. Singh \& Darroch (2000:56-57) found that most young people prefer to get information about sex from their friends, as well as other informal sources as opposed to schools and clinics. The debate about sex education with a focus on either abstinence or contraception has been highlighted by critics. More specifically, the question arises; what type of education system can prevent unplanned pregnancies and abortion? Women who received less or no education concerning abstinence or birth control from parents and schools were the most likely to be at risk of an unplanned pregnancy while those who received sex education that either focused on abstinence or contraception in school were less likely to have an unplanned pregnancy or abortion (Singh \& Darroch, 2000:56-57).

Studies also showed that there is a relationship between religion and sex education. Women who are not affiliated to a religion are more likely to experience an unplanned pregnancy. This may be due to the type of education received. Parents with Christian affiliation were more likely to teach their daughters about abstinence and to talk about the important of abstinence.

Story (1999: 35) highlighted that some females might see contraceptives to be irrelevant or even harmful to their life and these perceptions could result in unplanned pregnancies. Unplanned pregnancies could result in serious problems for the physical, psychological and social well-being of females and even for their nuclear as well as extended families. Women should therefore be knowledgeable about different types of contraception in order for them to be able to make informed decisions about the use of contraception as well as their children's future. Provision of adequate information about contraceptives could assist females to realize that effective utilization of contraceptives can successfully delay pregnancies until they have completed their schooling and or are financially capable/ stable to care for their children. Female students need knowledge to be able to make informed decisions and to evaluate their attitudes and beliefs about contraceptives. Watt (2001:226) found that the belief that condoms are difficult to use and interfere with sexual pleasure was perceived as a barrier to the use of condoms. Females were ashamed to use contraceptives. 49\% feared parental reaction should their contraceptive use be discovered and $43 \%$ did not trust contraceptives at all. Thus 
female attitudes of shame for using contraceptives, fear of parental disapproval and distrust in the efficacy of contraceptives all pose possible barriers to females' utilization of contraceptives to prevent unplanned pregnancies.

\subsection{Motivators and Hindrances to Students' utilization of contraceptives}

Past studies showed that the moderating factors that could influence students' non-utilization of contraceptives includes demographic factors, such as age, gender and, and cultural / traditional beliefs and practices. Age is a very vital aspect when it comes to the utilization of contraceptives. However the ages of female students could be important in identifying the high risk age groups in order to make concerted efforts to provide such age groups with appropriate health education opportunities. Students may not use contraceptives out of ignorance and the unavailability of contraceptives. They may also not make use of contraceptives because they are lacking enough information or they are not educated about the utilization of contraceptive, their benefits and effects. Students' age might influence their decision to engage in sexual intercourse and contraceptive non- utilization. Story (1999: 19) states that if sexual and relationship education is started at an early age, prior to sexual debut, such knowledge could help both male and female students to delay their first sexual encounters. Female students need knowledge about contraceptives before sexual activities commence in order to prevent unplanned pregnancies and reduce the number of female pregnant students on campus. Thus sex education needs to be considered. There might also be gender differences in knowledge, attitudes and behaviour among students of the University towards the contraceptives. Both female and male students may need interventions that could improve their sexual knowledge and skills, clarify attitudes and beliefs and enhance discussions and negotiation skills (Watt, 2001:227).

McBurney (2001:320) argued that social values, beliefs and practices influence decision making about the use of contraception. Some beliefs are beneficial and others are not. Students are influenced by socio-psychological variables in deciding about initiating sexual relations and contraceptives use, possibly allowing their individual perceptions to be greatly influenced by peer influence and expectations. Students are coming from different cultural backgrounds, religion or traditions and might be influenced by different factors, or by the same factors but to different extents. This affects their decisions to use contraceptives. Values and norms are important in cultures because they tell us what should be done and what should not be done. In many cultures young people or unmarried people are not allowed to engage in sexual intercourse without following some tradition. Ethnic background, educational level, socio-economic class, and local community standards are interrelated factors in shaping sexual ideas and behaviors. Most of the educated women tend to fetch greater bridal wealth (known as 'lobola' in many South African traditional cultures) which may encourage parents to support their daughters' schooling, and perhaps their return to school following childbirth. However, encouraging their daughters to use contraceptives in order to complete their schooling prior to childbearing could be problematic for many parents especially those living in traditional communities. Cultural/traditional factors could pose a problem to female utilization of contraceptives leading to unplanned pregnancies. According to Gama (2008), students should be informed about the benefits of contraception. Fathalla (1997:64) argued that contraception is the woman's power to control her fertility and be able to complete her education, maintain gainful employment and make independent marital decisions. The use of contraceptives saves women's lives and improves their health by allowing them to prevent unplanned pregnancies. Lives are saved from high risk pregnancies or unsafe abortions. Effective use of condoms can prevent maternal deaths, cancers and STIs including HIV and AIDS. By delaying childbearing, through the use of effective contraceptives, female students would be acting in the interest of their future children because infant mortality rates are reportedly higher for babies born to adolescent mothers than for babies born to women in their twenties or thirties. Contraceptive use saves children's lives by allowing individuals and couples to delay and space births thereby providing greater opportunities for emotional support from the parents for each child. In addition the parents are able to provide for each child's physical needs. Contraceptive use also helps men to provide better lives for their families with less emotional and financial strain than with having to provide tor a large family. Contraceptives provide parents with the freedom to choose when to have children, how many children to have and at what intervals.

\subsection{The attitude of undergraduate towards contraceptive use}

According to Ugoji (2008), there is a significant relationship between students' attitudes towards contraceptive use and their knowledge of contraception. Similarly, Orubuloye et al (1991) reported that attitude of young adults and adolescent affect their knowledge of reproduction. Similarly, Eggieston et al. (1999) who investigated sexual attitude and behaviour among adolescents revealed that sexual attitude and behaviour among adolescents have been significantly shaped by socio-psychological factors and consequently affect their knowledge of contraception. Thus young adult need better sex 
education and greater access to family planning services. Eggieston et al. (1999) further concluded that there is no significant difference between the attitude of male and female students towards the contraceptives use. Similarly, Spelzer et al. (2001) that investigated the gender differences in adult attitude towards reproductive behaviour of adolescents revealed that on the average, both male and female adults share similar views towards reproductive behaviour of adolescents. However, women hold a more conservative attitude than men towards adolescent sexuality. $58 \%$ of adult women and $48 \%$ of adult men disapprove premarital sex among adolescents. In other study on attitude towards abortion and contraception among secondary school girls, a near collaborative finding was reported in which an investigation of first sexual intercourse of adolescents boys and were established by Oronsaye and Odiase (1983). In their study the average of 15 years was established for girls and 16 years for boys. There is therefore a tendency in the literature to conclude that students attitude towards contraceptive use could be explained on the basis of social and demographic variations.

\section{The Present Study}

In spite of increasing rates of teenage pregnancies and unsafe abortion, not much research has been done on the knowledge, attitudes and practices of university students, with respect to unintended pregnancy. Very often, female students in tertiary institutions are at an age and in a social context, where they are susceptible to unintended pregnancy, and to the consequences of unsafe abortions. These have been linked to an array of social and economic consequences as well as health risks. The need to devise steps aimed at reducing the incidence of repeated unwanted pregnancy and unsafe abortion among this group of 'high risk' youths has therefore become urgent. This study sought to investigate the level of knowledge that tertiary education students at the University of Zululand have about contraceptives and means of preventing unwanted pregnancy. Furthermore, the study attempts to unravel factors that mediate the level of use and perceived and experienced risks in the use of contraceptives among University students. The study hypothesized as follows:

$\mathrm{H1}$ : Students' knowledge of contraceptives is correlated with social demographic factors

H2: Students' use of contraceptives is correlated with social demographic factors

H3: Students' perceived risk of contraceptives is correlated with social demographic factors

$\mathrm{H} 4$ : There is a relationship between students' knowledge and perceived risk of contraceptives

H5: There is a relationship between students' knowledge and use of contraceptives

H6: There is a relationship between students' use and perceived risk of contraceptives.

\section{Research Method}

Sample size for the survey was calculated using the Raosoft online sample size calculator (http://www.raosoft.com/samplesize.html). Based on the estimated population of the University of Zululand, at a standard error margin of $5 \%$, a confidence level of $95 \%$, and a $7.8 \%$ response distribution, a sample size of 80 was derived. Sample elements were selected using simple random sampling by drawing units from the target population which comprise of students of University of Zululand. Data was collected through self-completion-questionnaires. Data was coded and analyzed using the Statistical Package for the Social Sciences (SPSS). Scales were constructed using Principal Components Analysis (PCA) thus Kaiser Meyer Olkin (KMO) test of sample size adequacy and Bartlett's Test of Sphericity (BTS) scores are presented. In addition, means and Standard Deviations (SD) of scale items are reported. All scales were saved in SPSS after extraction for further bivariate tests. Relationships between variables were tested using bivariate correlation.

\subsection{Scales and Measures}

Table 1: KMO and BTS for all scales

\begin{tabular}{|l|c|c|c|c|}
\hline & KMO & BTS & Df & Sig. \\
\hline KNOWCO & .887 & 391.338 & 36 & .000 \\
\hline USCONTRA & .689 & 407.429 & 36 & .000 \\
\hline PERUSEF & .653 & 555.532 & 6 & .000 \\
\hline PERISU & .866 & 401.566 & 36 & .000 \\
\hline EXPROB & .694 & 625.557 & 105 & .000 \\
\hline
\end{tabular}




\subsubsection{Knowledge of Contraceptives (KNOWCO) Scale}

Nine questionnaire items were used to elicit the respondents' Knowledge of Contraceptives (KNOWCO). In order to determine the mean rating of these items and the extent of the individual item's contribution to extracted factor, factor reduction was conducted using Principal Component Analysis on the nine items. The result (see table 1) showed that PCA was appropriate for the items given KMO $=.887, \mathrm{BTS}, \mathrm{X} 2=391.338(\mathrm{df}=36), \mathrm{p}<.000$ One factor (KNOWCO), accounting for $67.3966 \%$ of variance in the outcome was extracted (see table 2). The result further showed that the most well-known form of contraceptives to tridents was the condom, mean=4.09, SD=1.531(see table 3).

Table 2: Total Variance Explained/Extracted for all scales

\begin{tabular}{|l|c|}
\hline & Total Variance Explained/Extracted \\
\hline KNOWCO & 67.396 \\
\hline US'CONTRA & 57.405 \\
\hline PERUSEF & 50.960 \\
\hline PERISU & 69.154 \\
\hline EXPROB & 75.454 \\
\hline
\end{tabular}

\subsubsection{Use of Contraceptives (FREQUQO)}

Nine questionnaire items were used to elicit the respondents' USCONTRA. In order to determine the mean rating of these items and the extent of the individual item's contribution to extracted factor, factor reduction was conducted using Principal Component Analysis on the thirteen items. The result in table 5.18 showed that PCA was appropriate for the items given $\mathrm{KMO}=.689$, BTS, $\mathrm{X} 2=407.429(\mathrm{df}=36), \mathrm{p}<.000$. One factor USCONTRA, accounting for $57.405 \%$ variance in the outcome was extracted (see table 2).

Table 3: Descriptive Statistics for KNOWCO USCONTRA and PERISU

\begin{tabular}{|l|c|c|c|c|c|c|}
\hline \multirow{2}{*}{} & \multicolumn{2}{|c|}{ KNOWCO } & \multicolumn{2}{c|}{ USCONTRA } & \multicolumn{2}{c|}{ PERISU } \\
\cline { 2 - 8 } & Mean & SD & Mean & SD & Mean & SD \\
\hline Condoms & 2.14 & 2.567 & 4.87 & .516 & 3.38 & 1.328 \\
Emergency Contraceptives pills & 3.05 & 1.545 & 3.97 & 1.510 & 3.06 & 1.218 \\
Sterilization & 3.86 & 1.235 & 4.78 & .762 & 3.21 & 1.043 \\
Intrauterine devices & 3.94 & 1.177 & 4.70 & .925 & 3.32 & .952 \\
Vaginal ring & 3.92 & 1.204 & 4.81 & .752 & 3.31 & 1.079 \\
Diaphragms & 4.03 & 1.116 & 2.16 & 1.363 & 3.21 & 1.092 \\
Contraceptives sponges & 4.09 & 1.009 & 4.82 & .747 & 3.30 & 1.014 \\
Progestin-only pills & 3.97 & 1.057 & 4.84 & .649 & 3.31 & 1.079 \\
Injectable birth control & 3.09 & 1.531 & 4.19 & 1.378 & 3.18 & 1.315 \\
\hline
\end{tabular}

As shown in table 3, the most frequently used contraceptives among students is the condom, mean= $4.87, \mathrm{SD}=.516$.

\subsubsection{Perception of usefulness of Contraceptives (PERUSEF)}

Table 4: Descriptive Statistics PERUSEF

\begin{tabular}{|l|c|c|}
\hline & Mean & Std. Deviation \\
\hline To prevent pregnancy & 1.67 & 1.118 \\
To prevent both pregnancy and STI & 2.08 & 1.347 \\
To prevent both unintended pregnancy and STI & 1.96 & 1.344 \\
To fight against disease & 3.30 & 1.275 \\
\hline
\end{tabular}

PCA of the nine items was used to construct the PERUSEF scale, the results produced a KMO $=0.653$, and $B T S, X^{2}=$ 55.532 ( $d f=6$ ), $p<.005$. The results (see table 4) further showed that students perceive that the most useful benefits from contraceptives is that it helps 'to fight against disease', mean $=3.30, S D=1.275$, with a variance of $50.960 \%$. With ravaging HIVIAIDS in South Africa, it is not surprising that students preponderantly perceive that contraceptives like condoms are a valuable protection against diseases, especially STIs. PCA extracted PERUSE which accounts for $50.960 \%$ of variance (See table 2). The variable was saved in SPSS and used in further bivariate analysis. 


\subsubsection{Perception of Risk in contraceptive Use (PERISU)}

The PERISU scale was computed from nine items that were meant to measure students' extents of fear of risks in the use of contraceptives. PCA factor reduction of the nine items produced a $\mathrm{KMO}=0.866$, and $\mathrm{BTS}, \mathrm{X}^{2}=401.566$ (df $=36$ ), $p<.000$ (see table 1). As table 3 further showed, the item contraceptive that students have experienced the most risk in using is the condom, with mean $=3.38, \mathrm{SD}=1.328$. PCA extracted PERISU which accounts for $56.018 \%$ of variance (See table 2). The variable was saved in SPSS and used in further bivariate analysis.

\subsubsection{Experience of Problems in the Use of Contraceptive (EXPROB)}

Table 5: Descriptive Statistics for EXPROB

\begin{tabular}{|l|c|c|}
\hline & Mean & Std. Deviation \\
\hline Condom can burst & 4.83 & .616 \\
Pain & 3.99 & 1.262 \\
Bleeding & 4.25 & 1.226 \\
Complications from surgery & 4.71 & .809 \\
Weight gain & 4.52 & 2.654 \\
Mood changes & 4.58 & .908 \\
Depression & 4.65 & .855 \\
Headaches and dizziness & 4.32 & 1.240 \\
Changes in period & 4.18 & 1.364 \\
Lower interest in sex & 4.39 & .975 \\
Upset stomach & 4.61 & .920 \\
Blood clots & 4.71 & .666 \\
Heart attack & 3.86 & 1.315 \\
Varginal discharge & 4.31 & 1.184 \\
\hline
\end{tabular}

The EXPROB scale was computed from nine items that were meant to measure the actual experience of problems by students in the use of contraceptives. The nine items produced a KMO $=.694$, and BTS, $X 2=625.557$ (df $=105$ ), $p<.000$ (see table 1). As table 5 shows, that most commonly experience problem in the use of contraceptives was a burst condom, mean $=4.83, \mathrm{SD}=.616$. EXPROB was extracted accounting for $75.454 \%$ of variance in the outcome (see table 2).

\section{Results and Discussions}

\subsubsection{Knowledge of Contraceptives (KNOWCO)}

Social Demographic determinants of KNOWCO

Table 6: Zero-order correlations for KNOWCO and demographics

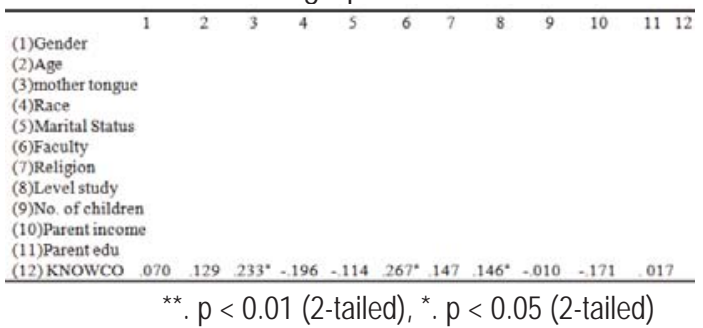

Table 6 reports zero order correlations for the knowledge of contraceptives and social demographic factors. The result shows that (KNOWCO) is predicted by mother tongue, $r=.233, p<0.05$ (2-tailed), level of study, $r=.146, p<0.05$. The result also showed that KNOWCO correlates with faculty $r=267, p<0.05$ (2-tailed). Apart from these two variables, the relationships between KNOWCO and all other social demographic variables fell below the acceptable levels of statistical significance. Surprisingly and contrary to what has been earlier reported in the literature (for example, Ugoji, 2008), the result showed an insignificant correlation between KNOWCO and gender, $r=0.070, p>0.05$. This result is perhaps due 
to minor sampling errors. Orubuloye et al (1991) reported that attitude young adults and adolescent affect their knowledge of reproduction. Other studies on attitude towards contraceptives reported a relationship between students' attitude and their knowledge of contraception (also Eggieston et al., 1999). Sexual attitude and behaviour among adolescents have been significantly sharpened by socio-psychological factors and consequently affect their knowledge of contraception. Thus there is a significant relationship between student 'attitudes towards contraceptive use and their knowledge of contraception

\subsubsection{Use of Contraceptives (USCONTRA)}

Social Demographic correlates of USCONTRAI2

Table 7: Zero-order correlations for USCONTRA and demographics

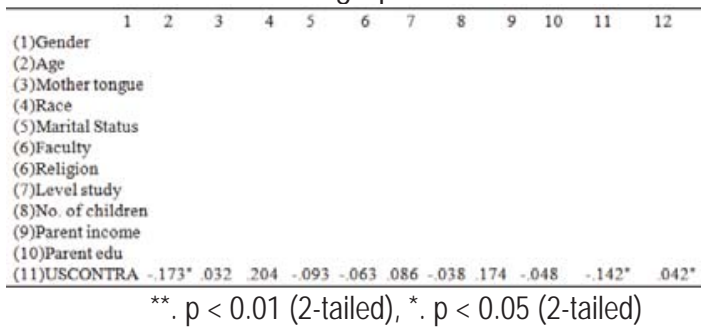

Table 7 shows zero order correlations between social demographic variables and the use of contraceptives (USCONTRA). The result showed that USCONTRA is predicted gender, -.173 and parent level of education $r=042, p<$ 0.05 (2-tailed). The result further showed that USCONTRA is negatively correlated with parents income $r=.142, p<0.05$ (2-tailed). These results imply that parental levels of education and income are significant predictors of students' use of contraceptives. With a high number of students from economically disadvantaged backgrounds, and low educational qualifications, the potential for these students to use contraceptives is low. This is more so with contraceptives that are not provided free of charge. Past studies have confirmed the importance of parents' socio economic background to students' access to and use of contraceptives (Gama, 2008; Ugoji, 2008). The result also reveals in that there is a significant difference between the use of contraceptives among males and females. For example, Babbie, (2004:20) reported that female students who are sexually active were less likely to use contraceptives, which puts them at a high risk of unplanned pregnancy. While some past studies have reported a contrary result, the preponderance of the use of condoms among students in the present sample may account for the significance level obtained. Story (1999) argued that majority of today's college students engage in sexual intercourse generally with multiple partners. Some of these sexually active students use contraception; many do not. Since students are engaging in intercourse and some are failing to use contraceptives properly or not using contraceptives at all they often report either experiencing or being involved in unplanned pregnancy. Young people who commenced sexual activity before high school were more likely to have experienced an unintended pregnancy than those who initiated sex later; they may have been less aware of the risks for pregnancy and thus used contraception less often. This pattern may explain the high rate of pregnancy among early initiators in our study. Further, earlier initiation of sexual intercourse exposes students to an extended period during which they are at risk for becoming pregnant.

\subsubsection{Perception of Risk of Use of Contraceptive (PERUSEF)}

Social Demographic determinants of PERUSEF

Table 9: Zero-order correlations for PERUSEF and demographics

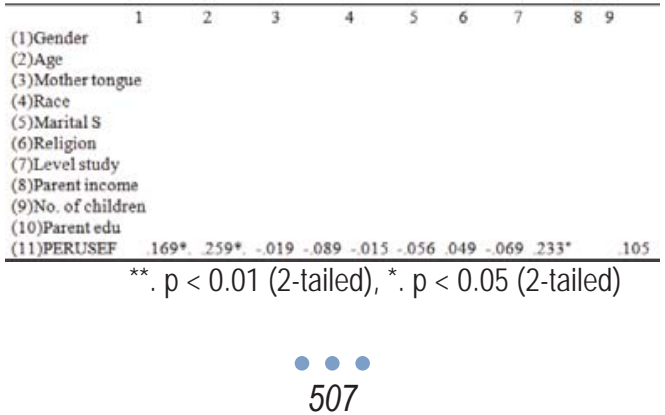


Table 9 depicts the zero order correlations for the relationships between PERUSEF and social demographic variables. The result show that PERUSELF is predicted by gender $r=0.069, p<0.05$ (2-tailed), age, $r=.259, p<0.05$ (2-tailed). The result also showed that the relationship between PERUSEF and number of children is significant; $r=.233, p<0.05$ (2tailed). The result implies that older students are more perceptive of the usefulness of contraceptive and that there is a difference in the perception of students by gender. Interestingly however, the result showed that the relationship between PERUSEF and number of children is negative. This may be interpreted to connote that respondent who have more children are less trustful of contraceptives. Fathalla (1997:64) cited by Story (1999:34) argued that contraception is the woman's power to control her fertility and be able to complete her education, maintain gainful employment and make independent marital decisions. The use of contraceptives saves women's lives and improves their health by allowing them to prevent unplanned pregnancies.

\subsubsection{Perception of Risk in the Use of Contraceptives (PERISU)}

\section{Social Demographic determinants of PERISU}

Table 10: Zero-order correlations for PERISU and demographics

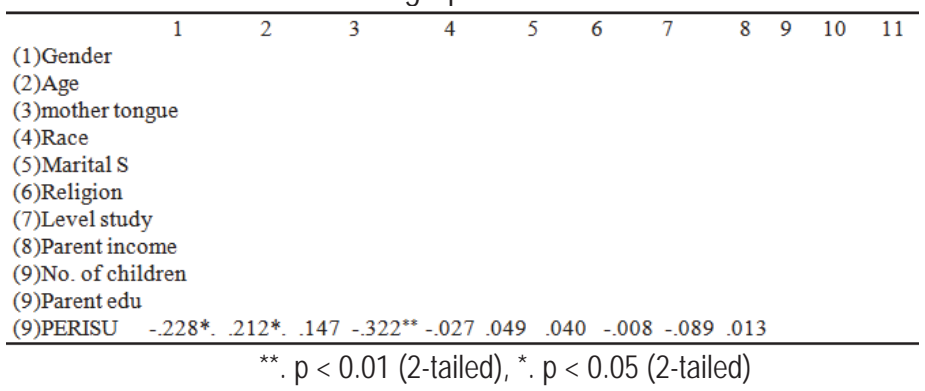

Table 10 reports the correlation coefficients for the relationship between the perception of Risk in the use of contraceptive, PERISU, and social demographic variables. The result showed that PERISU is predicted by gender, $r=$ .223 , $p<0.05$ (2-tailed), age $r=0.212, p<0.05$ (2-tailed), race, -.322, $p<0.05$ (1-tailed). These results imply that gender and age of respondents predict perception of risk in the use of contraceptives. Ugoji (2008), in the study concluded in Burkina Faso noted that the reluctance to use modern methods stemmed from a fear that uses might cause infertility that the contraception pill might produce. Other risks and disadvantages of contraceptives include migraine/ headaches. Women with classic migraines (true vascular headaches) and associated neurologic symptoms are often advised to use another type of contraceptive because high-dose oral contraceptives have been linked with headaches and strokes. Progestogen can cause smooth muscle relaxation, which is commonly manifested as an increase in gastroe- sophageal reflux, and it may also worsen pre-existing depression, a condition that remains undiagnosed in many women. In addition, the use of progestogen in women with a history of gallbladder disease or stones can lead to symptomatic attacks such as cholestasis jaundice (particularly in women who had jaundice during pregnancy) and to cholecystectomy. Available data on whether oral contraceptive use increases the risk of breast cancer are conflicting. Many epidemiologic studies show an increased relative risk, especially oral contraceptive use at a young age (Orasanye and Odiase, 1983).

\subsubsection{Experience of Problems in the Use of Contraceptives (EXPROB)}

Table 11: Zero-order correlations for EXPROB and demographics

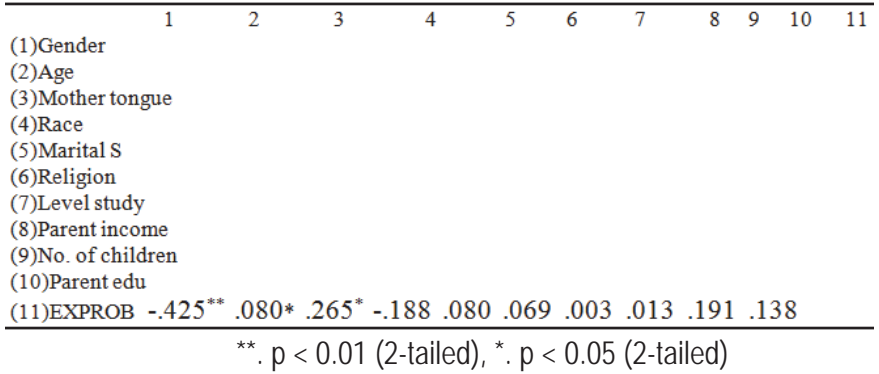


Table 11 shows the result of zero order correlation for the relationships between EXPROB and social demographic variables. The result shows that EXPROB is correlated with gender, -.425, $p<.0 .05$ (1-tailed), age, $r=.080, p<.0,05$ (2tailed). All other relationships fell below acceptable levels of statistical significance. Some contraceptives constitute to risks while on the other side they help to fight against the spread of diseases e.g. STIs. Contraceptives plays a major role in preventing unintended pregnancy by also reducing the high rate of abortions, some people use contraceptives to fight against diseases.

\subsection{Knowledge, Use, Risk and Experience of Problems in the use of Contraceptives}

Table 12: Zero Order Correlations for the relationships between KNOWCO, USCONTRA, PERISU and EXPROB

\begin{tabular}{|c|c|c|c|c|c|c|}
\hline & & KNOWCO & USCONTRA & PERUSEF & PERISU & EXPROB \\
\hline \multirow{2}{*}{ KNOWCO } & Pearson Correlation & 1 & $.380^{* *}$ & $.334^{*}$ & .016 & $-.227^{*}$ \\
\hline & Sig. (2-tailed) & & .001 & .003 & .003 & .048 \\
\hline \multirow{2}{*}{ USCONTRA } & Pearson Correlation & $.380^{* *}$ & 1 & .112 & $.276^{*}$ & $479^{* *}$ \\
\hline & Sig. (2-tailed) & .001 & & .330 & .016 & .000 \\
\hline \multirow{2}{*}{ PERUSEF } & Pearson Correlation & $.334^{*}$ & 112 & 1 & .218 & .040 \\
\hline & Sig. (2-tailed) & .003 & .330 & & .058 & .731 \\
\hline \multirow{2}{*}{ PERISU } & Pearson Correlation & $.116^{*}$ & $.276^{*}$ & .218 & 1 & .218 \\
\hline & Sig. (2-tailed) & .003 & .016 & .058 & & .062 \\
\hline \multirow{2}{*}{ EXPROB } & Pearson Correlation & $-.227^{\star}$ & $.479^{* *}$ & .040 & .218 & 1 \\
\hline & Sig. (2-tailed) & .048 & .000 & .731 & .062 & \\
\hline
\end{tabular}

Table 12 shows correlation coefficients between KNOWCO, USCONTRA, PERSUSEF, PERISU and EXPROB. The result showed that KNOWCO is correlated with USCONTRA, $r=0.380 ; p<0,05$ (1-tailed), PERUSEF $r=.334, p<0.05$, (2tailed) and EXPROB, $r=-.227, p<0.05$, (2-tailed). The result further showed that PERISU predicts USCONTRA, $r=.276$, $p<0.05$ (2-tailed). Similarly the result showed that EXPROB predicts USCONTRA, $r=.479, p<0.05$. The results preponderantly confirm what has been reported in the literature (Ugoji, 2008; Gama, 2008; Fathalla, 1997; Story, 1999; Chimere-Dan, 1996; Oroboloye, 1991). The major significance of these results is that the knowledge of contraceptives predicts the use of contraceptives and the perception of usefulness of contraceptives. It also implies that knowledge of contraceptives is correlated with the experience of problems in the use of contraceptives. The importance of knowledge of contraceptives has therefore been underscored.

\section{Conclusion}

The result of the present study has shown that the knowledge, use and perceived problems in the use of contraceptives is predicated upon young people's social and demographic characteristics most importantly, the study showed that gender and ager are significant variables in understanding knowledge and use of contraceptives among university students. Past studies showed that having heard of contraceptives was significantly different for men compared to women and for respondents of different age groups (see for example, Ugoji, 2008). Ugoji (2008) reported that there is a significant relationship between student's attitudes towards contraceptive use and their knowledge of contraception. This corroborates the findings of the present study. Orubuloye et al. (1991) similarly reported that attitude of young adults and adolescent affect their knowledge of reproduction. In other studies this relationship between students' attitude and their knowledge of contraception has been well established. For example, Eggieston et al (1999) who investigated sexual attitude and behaviour among adolescence concluded that sexual attitude and behaviour among adolescents have been significantly sharpened by socio-psychological factors and consequently affect their knowledge of contraception. Consequently therefore, young adult need better sex education and greater access to family planning services.

Spelzer et el. (2001) reported that on average, both male and female adults share similar views about reproductive behaviour of adolescents. However, women hold a more conservative attitude than males towards adolescent sexuality. Spelzer et el. (2001) in their study reported that $58 \%$ of adult women and $48 \%$ of adult men disapprove pre-marital sex among adolescents. In other studies on attitudes towards abortion and contraception among secondary school girls, a near collaborative finding was reported (see Oronsaye and Odiase (1983). However, females may be expected to have more knowledge of a wider array of contraceptives because of the number of contraceptives that are used by females is more than those for males who often use only condoms. 
The study has found that there are a number of factors that inhibit the use of contraceptives among young people. For example, parental levels of education and income, and students' access to enough funds to buy contraceptives that are not provided for free determine levels of use of contraceptives. The apartheid regime in South Africa brought African education under control of the government and extended apartheid to black schools. Thus where parents are not educated or lacking education their children often lack a lot of information on life plan and early family planning decisions. The study showed clearly that students' knowledge of contraceptives affect their use of contraception.

\section{Recommendations}

Consequent upon the findings of the study, the following recommendations are proposed in order to enhance the levels of knowledge and use of contraceptives among young people. These recommendations are that:

$\checkmark$ Males and females should receive equal education about the correct use of contraceptives.

$\checkmark$ It is very important to always give orientation to new student about different kinds of contraceptives in order to reduce the number students who become pregnant upon entering higher institutions.

$\checkmark$ It is advisable to provide contraceptives like condoms in the toilets at students' residences in order to make easier for the students to get contraceptives whenever they need to use them.

\section{References}

Ahman, E. and Shah, I. (2007). Unsafe Abortion: Global estimates of unsafe abortion and Associated Mortality in 2003. Geneva: WHO.

Babbie, E. (2004). The Practice of Social Research (10th edition). Oxford: Clarendon Press.

Baker, R.L. (1999). The Social work Dictionary. Washington, DC: NASW Press.

Barry, S. (1993). The facts about Drug Use: Coping with drugs and alcohol. Berlin: Haworth Medical Press.

Chimere-Dan, O. (1996). Contraceptives Prevalence in rural South Africa. Family planning perspective, 229(1):4-9.

Corblin. CB. (2006). Concepts of fitness and wellness: A comprehensive lifestyle Approach. New York: McGraw-Hill Company.

Eggleston, E, Jackson, J \& Hardee, K. (1999). Sexual attitudes and behaviour among young adolescents in Jamaica. International Family Planning Perspectives 25(2):78-91.

Fathalla, M.F. (1997). From Obstetrics and Gynaecology to women's health. New York: Parthenon.

Gama, N.N. (2008). The effects of unplanned Pregnancy on Female Stu dents of the University of Zululand. Unpublished Masters Dissertation, University of Zululand.

Makhubele, J.C. (2004). The impact of culture on the prevention and treatment of HIVIAIDS amongst people in low resourced areas: social work perspective. South Africa: University of North West.

McBurney, D.H., IVlrite, T.L. (2007). Research Methods. New York: Vicki Knight.

McWhiter, J.J. (2004). At Risk Youth: A Comprehensive Response. London: Oxford University Oxford press.

Oronsaye A.U. and Odiase G.I. (1983). Attitudes toward abortion and contraception among Nigerian secondary school girls. International journal of Gynecology and Obstetrics, 21(5): 423-426.

Orubuloye, I. O., Caldwell, J. C. \& Caldwell, P. (1993). African women's control over their sexuality in an era of AIDS: A study of the Yoruba of Nigeria. Social Science and Medicine, 37(7): 859-872.

Singh S. \& Darroch J.E. (2000). Adolescent pregnancy and childbearing. Austria: United Nations publications.

Sowetan live 2011. Teenage pregnancy in Soweto. @ http://scholar.lib.vt.edu/theses/available/etd. Downloaded on 23 September 2013.

Story, W.A. (1999). The effect of unplanned pregnancy among college woman. Virginia: University press

Spelzer, IS, Muller, SA \& Amegee, K. 2001. Gender differences in adult perspectives on adolescent reproductive behaviours: evidence from Lome, Togo. International Family Planning Perspectives, 27(4):178-185.

Thompson, B, Fraser, C \& Anderson, D. 1997. Sexual relationships: some aspects of first sexual relationships in females with special reference to those aged under 16. Health Education Journal, 52(2):63-67.

Ugoji F.N. (2008). Attitudes of Undergraduates toward Contraceptive use. Pakistan journal of social sciences, 5(1): 111-115.

Watt, L.D. 2001. Pregnancy prevention in primary care for adolescent males. Journal of Pediatric Health Care, 15(5):223-228. 